\title{
Do consumers 'Get the facts'? A survey of alcohol warning label recognition in Australia
}

\author{
Kerri Coomber ${ }^{*}$, Florentine Martino, I. Robert Barbour, Richelle Mayshak and Peter G. Miller
}

\begin{abstract}
Background: There is limited research on awareness of alcohol warning labels and their effects. The current study examined the awareness of the Australian voluntary warning labels, the 'Get the facts' logo (a component of current warning labels) that directs consumers to an industry-designed informational website, and whether alcohol consumers visited this website.

Methods: Participants aged 18-45 (unweighted $n=561$; mean age $=33.6$ years) completed an online survey assessing alcohol consumption patterns, awareness of the 'Get the facts' logo and warning labels, and use of the website.

Results: No participants recalled the 'Get the facts' logo, and the recall rate of warning labels was $16 \%$ at best. A quarter of participants recognised the 'Get the facts' logo, and awareness of the warning labels ranged from 13.1-37.9\%. Overall, only $7.3 \%$ of respondents had visited the website. Multivariable logistic regression models indicated that younger drinkers, increased frequency of binge drinking, consuming alcohol directly from the bottle or can, and support for warning labels were significantly, positively associated with awareness of the logo and warning labels. While an increased frequency of binge drinking, consuming alcohol directly from the container, support for warning labels, and recognition of the 'Get the facts' logo increased the odds of visiting the website.

Conclusions: Within this sample, recall of the current, voluntary warning labels on Australian alcohol products was non-existent, overall awareness was low, and few people reported visiting the DrinkWise website. It appears that current warning labels fail to effectively transmit health messages to the general public.
\end{abstract}

\section{Background}

Globally, alcohol is the third highest cause of disease and disability, and $4 \%$ of deaths worldwide can be attributed to alcohol [1]. Eighty four percent of the Australian adult population are regular consumers of alcohol [2]. Approximately one in five Australians aged 14 years or older drink at levels that put them at risk of harm over their lifetime [2] and more than a quarter of Australian adults consume alcohol at least once a month at levels that put them at risk of acute accident or injury [3]. Despite the patterns of alcohol consumption in Australia, $78 \%$ of adults believe there is a problem of excess drinking or alcohol abuse within society [4]. However, current policies fail to adequately address the full extent of the problem. In line with successful tobacco control measures, recommendations have been made to apply mandatory warning labels on alcohol

\footnotetext{
* Correspondence: k.coomber@deakin.edu.au

School of Psychology, Faculty of Health, Deakin University, Locked Bag 20001, Geelong 3220, Australia
}

products, at point of sale, and on advertising to provide much needed health information for drinkers [5-8]. Warning labels, in the context of a comprehensive set of interventions, have the potential to inform consumers of the likely harms of risky drinking, and how consumers might reduce this risk $[7,9,10]$.

The comprehensive literature base for tobacco warning labels indicates that such an intervention can be highly successful at changing the attitudes and behaviours of smokers. Tobacco warning labels increase health knowledge and perceptions of risk, aid cessation, and help to prevent smoking initiation [11]. Tobacco label literature also provides transferable knowledge of the key aspects that make warning labels effective, including: position on the label, size of warnings, message type, and warning refreshment [11]. Using tobacco labelling as a 'best practice' base [7], there is potential to develop alcohol warning labels that achieve similar outcomes. 
In July 2011, DrinkWise - an alcohol industry 'social aspects/public relations' organisation [12, 13] - implemented new voluntary consumer messages on alcohol products. The introduction of these messages were in response to the recommendation by an independent government review that all alcohol product labels contain a health warning [14]. These voluntary labels depict the core message of 'Get the facts', which encourages drinkers to visit the DrinkWise website to research the harms of drinking. According to information on the DrinkWise website, their website contains evidencebased information on alcohol that is designed to help communities take a healthier and safer approach to alcohol consumption. However, research indicates that DrinkWise and other international industry funded organisations, do not actually promote evidence-based interventions and alcohol-harm reduction strategies known to reduce alcohol-related harms [13, 15]. In conjunction with the 'Get the facts' logo, alcohol products may also include one of four messages or images: 'It is safest not to drink while pregnant'; an image of a silhouette of a pregnant woman with a strike through; 'Is your drinking harming yourself or others?'; or, 'Kids and alcohol don't mix' (see Fig. 1 for examples of these warning labels alcohol products).

The most recent audit of Australian alcohol warning labels showed that these labels are only depicted on approximately one in three alcohol products [16]. Further, current Australian warning labels have been criticised as being simply too small (less than $5 \%$ of the label), being located on the back of the label, utilising vague wording and images, and lacking visual impact to generate an emotional response $[9,17-20]$. There is a lack of research examining the effectiveness of alcohol warning labels within the context of alcohol policy more widely.
However, for warning labels to be most effective the messages conveyed within the label should be linked with other prevention initiatives, such as alcohol control advertising [7]. Such an approach would increase the exposure of the message and act to reinforce the messages on labels.

Studies on the effectiveness of alcohol warning labels have mostly focused on the mandatory text-based warnings used in the United States (US), with most research being quite dated [21, 5, 22, 7]. After the introduction of the US alcohol text warnings in 1989, there was a steady increase in free recall of these warnings from $3.8 \%$ in 1989-28.5 \% in 1993-1994 [23]. More recent research indicates that approximately $20 \%-30 \%$ of US adults recall the drink driving text warning [24]. However, these text-based warnings have minimal impact on behaviour change [7, 21]. Awareness of the mandatory US warning labels is highest amongst the youngest group of drinkers (18-29 years) and heavy drinkers due to the likelihood of greater exposure to the containers, and therefore the labels on them [25, 23]. However, these frequent users of alcohol find warning labels relatively less believable, suggesting that the warning label may be partially ignored or discounted by those that need the warning labels the most [26]. Additionally, those with a higher levels of education are more likely to freely recall warning labels [23], but there is no difference by education for prompted recognition of the label [25].

To date, there has been very limited research examining awareness of warning labels on Australian alcohol products. One recent report found that one-third of women were aware of the pregnancy silhouette warning label, and $20 \%$ were aware of the text-based pregnancy label [27]. However, there has been no research investigating whether consumers are aware of the 'Get the facts' logo, the other
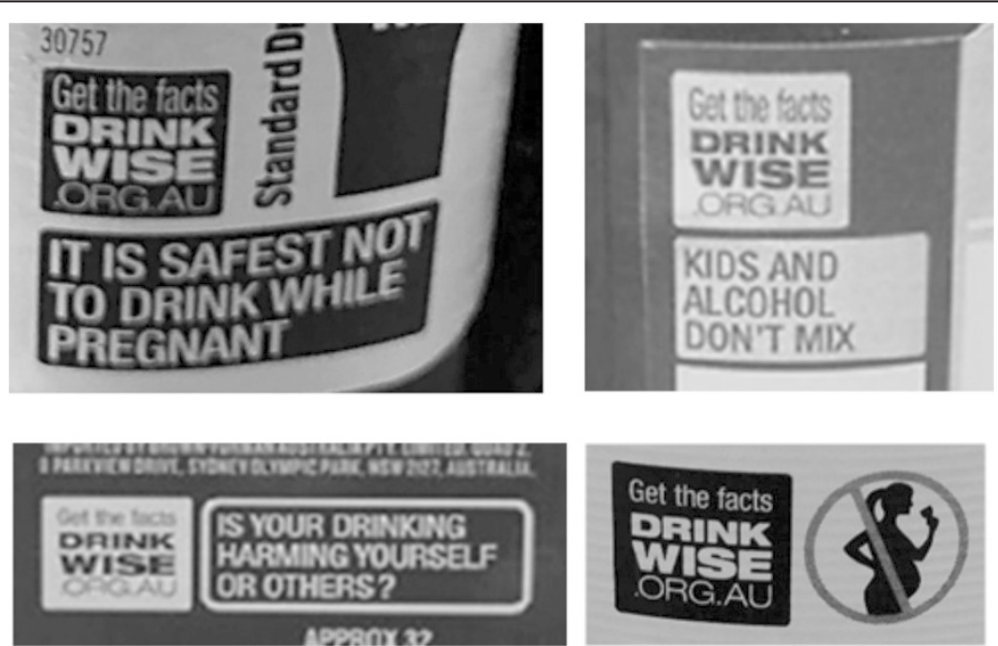

Fig. 1 Examples of current voluntary DrinkWise warning labels as used on alcohol products 
voluntary warning label messages, or if consumers visit the DrinkWise website. Therefore, the aim of the present study is evaluate awareness of the 'Get the facts' logo and alcohol warning labels, and to also evaluate consumer use of the DrinkWise website. Demographic predictors of awareness of the logo, warning labels, and use of the DrinkWise website will also be explored.

\section{Methods}

\section{Participants}

Participants were recruited using an online research panel (MyOpinions). In order to capture a wide range of demographics, panel members are recruited by MyOpinions through both online (e.g., banner ads, search engines) and offline (e.g., radio and print advertising) channels. Regular profiling of the online panel ensures that the demographic spread of panel members is representative of the Australian population. Quotas for data collection were set for gender (50/50 \%). A total of 1676 respondents commenced the survey. Of these, 885 participants were screened out of the survey due to being outside of the target age range of $18-45$ years $(n=869)$ or indicating that they never consumed alcohol $(n=16)$. An additional 230 participants dropped out of the survey at varying points after commencement. Due to the non-random nature of this missing data (i.e., participants chose to discontinue the survey) we opted not to replace this missing data and these responses were excluded. The final sample comprised 561 participants (weighted $n=555$ ). Table 1 provides details of the demographics and predictor variables.

\section{Measures}

\section{Recall and recognition of the 'Get the facts' logo and alcohol warning labels}

Participants were first asked how often they see warning labels on alcohol containers, followed by an open-ended item asking 'Which label(s) do you recall seeing?' Participants then typed in a brief description of the label to generate a measure of spontaneous warning label recall. Therefore, recall is defined as the spontaneous recall of a warning label in the absence of prompts or cues. The items assessing recall of a warning label were mandatory; that is, participants were unable to proceed in the survey until these items had been answered in order to prevent viewing warning label images that are presented later in the survey. Participant descriptions of the labels were categorised according to each of the warning labels and the 'Get the facts' logo. All descriptions that mentioned pregnancy were coded in the one category; that is, we did not code the three pregnancy labels separately.

To assess logo and warning label recognition, the 'Get the facts' logo and each label were then shown to participants. Participants were asked if they had seen this logo/label on any alcohol products. Thus, recognition is
Table. 1 Characteristics of participants

\begin{tabular}{|c|c|c|c|c|}
\hline & \multicolumn{2}{|c|}{ Unweighted data } & \multicolumn{2}{|c|}{ Weighted data ${ }^{a}$} \\
\hline & $\mathrm{N}$ & $\%$ & $\mathrm{~N}$ & $\%$ \\
\hline \multicolumn{5}{|l|}{ Gender } \\
\hline Male & 295 & 52.6 & 277 & 49.8 \\
\hline Female & 266 & 47.4 & 279 & 50.2 \\
\hline \multicolumn{5}{|l|}{ Age } \\
\hline $18-24$ & 98 & 17.5 & 132 & 23.7 \\
\hline $25-34$ & 190 & 33.9 & 200 & 35.9 \\
\hline $35-45$ & 273 & 48.7 & 224 & 40.4 \\
\hline \multicolumn{5}{|l|}{ Education } \\
\hline Less than tertiary & 317 & 56.5 & 314 & 56.6 \\
\hline Tertiary or above & 244 & 43.5 & 241 & 43.4 \\
\hline \multicolumn{5}{|l|}{ Frequency of binge drinking } \\
\hline Never & 185 & 33.0 & 180 & 32.5 \\
\hline Less than monthly & 240 & 42.8 & 246 & 44.3 \\
\hline Monthly & 85 & 15.2 & 83 & 15.0 \\
\hline Weekly & 43 & 7.7 & 39 & 7.0 \\
\hline Daily or almost daily & 8 & 1.4 & 7 & 1.2 \\
\hline \multicolumn{5}{|l|}{ Main alcoholic drink } \\
\hline Beer & 166 & 29.6 & 153 & 27.6 \\
\hline Wine & 155 & 27.6 & 150 & 27.1 \\
\hline Spirits & 115 & 20.5 & 119 & 21.5 \\
\hline Pre-mix & 86 & 15.3 & 96 & 17.2 \\
\hline Cider & 20 & 3.6 & 19 & 3.5 \\
\hline Other & 19 & 3.4 & 17 & 3.1 \\
\hline \multicolumn{5}{|c|}{ Drink directly from can or bottle } \\
\hline Never/not often & 170 & 30.3 & 168 & 30.2 \\
\hline At least sometimes & 391 & 69.7 & 388 & 69.8 \\
\hline \multicolumn{5}{|c|}{ Support for health warning labels } \\
\hline Neutral or opposed & 114 & 20.3 & 110 & 19.8 \\
\hline Support/strongly support & 447 & 70.7 & 445 & 80.2 \\
\hline
\end{tabular}

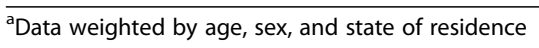

defined as participants identifying the logo/labels that they have previously seen on alcohol products, after exposure to images of the logo and labels. The spontaneous recall and prompted recognition responses were then combined to generate a measure of overall awareness. Awareness of a label was defined as the proportion of participants who freely recalled the warning label, plus the proportion who of participants who did not freely recall the label, but recognised it after being presented with an image of the label.

\section{Use of the DrinkWise website}

One item asked if participants had ever visited the DrinkWise website depicted in the 'Get the facts' logo 
and on each alcohol warning label (response options 'yes' or 'no').

\section{Alcohol use}

The binge drinking item from the Alcohol Use Disorders Identification Test (AUDIT-C) was used to measure frequency of short-term risky drinking occasions [28]. Items from the AUDIT-C have been validated for use in the general adult population $[29,30]$. This item asked 'How often have you had 6 or more units if female, or 8 or more units if male, on a single occasion in the last year?' (0 'never' to 4 'daily or almost daily').

Participants were also asked to select which type of alcoholic drink was their main drink of choice. Main alcoholic drink was categorised into beer, wine, spirits, pre-mix, cider, and other (consisting of unspecified alcoholic beverages and home-brew beer). Additionally, participants were asked how often they consume alcohol directly from the can or bottle; responses were dichotomised into 'sometimes, often, or very often' compared to 'not often, or never'.

\section{Demographics}

Data were collected on sex, age (categorised as 18-24 years, 25-34 years and 35-45 years for analysis), and highest educational attainment (coded as 'less than tertiary' or 'tertiary or higher'). Lastly, participants were asked how strongly they support the use of health warning labels on all alcohol beverages; responses were dichotomised into 'support or strongly support' compared to 'neither support or oppose, oppose, or strongly oppose'.

\section{Procedure}

The study was approved by the Human Research Ethics committee of Deakin University. Participants who were part of an opt-in panel were contacted about the study via email, with data collection via an online survey using SurveyMonkey. The email contained the plain language statement and a link to the survey. The online survey panel monitors survey completion by panel identification number, therefore, panel members are precluded from completing the survey more than once. Participants indicated consent to complete the survey by clicking on the survey link. Survey completion time was between $10-15 \mathrm{~min}$.

\section{Data analysis}

All analyses were undertaken using Stata 12.1 [31] and post-stratification population weights were applied (using the svy command with 'p' weights) that accounted for age, gender, and state of residence using 2011 Australian Census Data [32]. Multivariable logistic regression analyses were used to examine predictors of recognition of the Get the Facts logo, awareness of each of the warning labels, and visiting the DrinkWise website. Prior to analyses, multicollinearity between the independent variables was tested using pairwise correlations and the collin command. Correlations between predictor variables were low (maximum $r=0.27$ ), and the variance inflation factors were also low (mean $=1.09$; range $=1.04-1.15)$, indicating no issues with multicollinearity [33].

\section{Results}

Table 2 shows that no participants freely recalled the 'Get the facts' logo, while a quarter of participants recognised this logo. Participants had the highest rate of overall awareness of the pregnancy warning labels, just under one-fifth of participants stated they had awareness of 'Is drinking harming yourself or others?' and approximately $13 \%$ of participants were aware of 'Kids and alcohol don't mix'.

\section{Recognition of the 'Get the facts' logo}

Table 3 provides results for the multivariable logistic regression examining predictors of recognition of the 'Get the facts' logo. The following factors were associated with a significantly increased odds of recognising the logo: more frequently engaging in binge drinking; consuming alcohol directly from a can or bottle at least some of the time; and, supporting the use of health warning labels. Older participants were significantly less likely than 18-24 year olds to recognise the logo. No other significant demographic differences were found.

\section{Overall awareness of the warning labels}

The predictors of awareness of warning labels were largely consistent with those found for recognition of the logo. Participants who engaged in more frequent binge drinking, those who consumed alcohol directly from a can or bottle, and participants who supported the use of health warning labels were all significantly more likely to be aware of alcohol warning labels (see Table 4). Older participants were significantly less likely than 18-24 year olds be aware of any of the warning labels. For the 'Kids and alcohol don't

Table. 2 Weighted proportion of respondents who freely recalled or recognised each alcohol warning label, the 'Get the facts' logo, and overall awareness

\begin{tabular}{llll}
\hline & Recall & Recognition & $\begin{array}{l}\text { Overall } \\
\text { awareness }\end{array}$ \\
\hline 'Get the facts' logo & $0 \%$ & $25.3 \%$ & $25.3 \%$ \\
$\begin{array}{l}\text { It is safest not to drink while } \\
\text { pregnant }\end{array}$ & $16.1 \%$ & $34.3 \%$ & $37.9 \%$ \\
$\begin{array}{l}\text { Is your drinking harming yourself } \\
\text { Or others? }\end{array}$ & $1.5 \%$ & $18.2 \%$ & $19.5 \%$ \\
Kids and alcohol don't mix & $0.4 \%$ & $12.9 \%$ & $13.1 \%$
\end{tabular}

${ }^{\mathrm{a}}$ Overall awareness takes into account both recall and recognition ${ }^{b}$ Recall, recognition, and awareness of any of the three pregnancy warning labels

Note. Data weighted by age, sex, and state of residence 
Table. 3 Results of logistic regression models predicting recognition of the 'Get the facts' logo

\begin{tabular}{|c|c|c|}
\hline & OR $(95 \% \mathrm{Cl})$ & $\mathrm{p}$ \\
\hline \multicolumn{3}{|l|}{ Gender } \\
\hline Male & 1.00 & \\
\hline Female & $0.65(0.40-1.07)$ & .090 \\
\hline Age & Wald $x^{2} p<.001$ & \\
\hline $18-24$ & 1.00 & \\
\hline $25-34$ & $0.85(0.47-1.56)$ & .610 \\
\hline $35-45$ & $0.35(0.19-0.65)$ & .001 \\
\hline \multicolumn{3}{|l|}{ Education } \\
\hline Less than tertiary & 1.00 & \\
\hline Tertiary or above & $0.94(0.59-1.51)$ & .800 \\
\hline Binge drinking & $1.61(1.29-2.00)$ & $<.001$ \\
\hline Main alcoholic drink & Wald $x^{2} p=.358$ & \\
\hline Beer & 1.00 & \\
\hline Wine & $1.20(0.65-2.22)$ & .551 \\
\hline Spirits & $0.68(0.33-1.38)$ & .281 \\
\hline Pre-mix & $0.60(0.28-1.29)$ & .191 \\
\hline Cider & $0.79(0.21-2.92)$ & .726 \\
\hline Other & $1.56(0.56-4.40)$ & .397 \\
\hline \multicolumn{3}{|c|}{ Drink directly from can or bottle } \\
\hline Never/not often & 1.00 & \\
\hline At least sometimes & $1.75(1.02-3.01)$ & .041 \\
\hline \multicolumn{3}{|c|}{ Support for health warning labels } \\
\hline Neutral or opposed & 1.00 & \\
\hline Support/strongly support & $1.92(1.05-3.53)$ & .034 \\
\hline
\end{tabular}

mix' label, 25-34 year olds were significantly less likely to be aware of this label, while those with a higher level of education were significantly more likely to be aware of this label. No other significant differences for awareness of warning labels were found.

\section{Use of the drinkwise website}

Forty (7.3\% weighted) participants reported having visited the DrinkWise website. Of those 40 participants, 32 (80.4\%) visited the website due to seeing the logo, whereas eight $(19.6 \%)$ visited it for other reasons. An important predictor of visiting the website was recognition of the 'Get the Facts' logo; those who recognised the logo were over seven times as likely to visit the website as those who did not recognise the logo (see Table 5). Females were significantly less likely than males to have visited the DrinkWise website. In addition, wine drinkers and spirits drinkers were significantly more likely than beer drinkers to visit the website. As per the findings for awareness of the warning labels, more frequent binge drinkers, participants who consumed alcohol directly from a can or bottle, and those who supported the used of health-focussed warning labels were all significantly more likely to have been to the DrinkWise website.

\section{Discussion}

This is the first study to explore the factors that influence awareness of Australian alcohol warning labels. This study is also the first to determine predictors of consumers visiting the DrinkWise website. Frequency of binge drinking, drinking directly from a can or bottle, and support for warning labels were all found to have significant positive associations with recognition of the logo, awareness of the warning labels, and visiting the DrinkWise website. However, older drinkers and females were less likely to be aware of the warning labels and visit the website, respectively.

The rate of logo and warning label recall in the current study was five to 28 percentage points lower than the recall of the mandatory text warnings in the US $[23,24]$. This general low level of warning label recall could be attributable to one-third of Australian alcohol products displaying a warning label, usually taking up less than $5 \%$ of the label and on the back of the product [16]. However, the discrepancy in recall compared to the US studies may also be attributable to the US studies utilising telephone interviews rather than online surveys $[23,24]$. Participants in the current study demonstrated the highest rate of awareness for the pregnancy warning labels. This level of awareness is most likely due to the pregnancy silhouette being the most common warning used [16] and pictorial labels being more noticeable [7].

The overall lack of awareness of warning labels may also stem from consumers misunderstanding what constitutes a health warning. Many young drinkers often confuse warning labels with 'drink responsibly' messages often displayed on product labels [34]. In our study, $22.8 \%$ (weighted) of participants freely recalled either standard drink information or drink responsibly message when asked to describe a warning label - nearly two times higher than the percentage of participants who freely recalled a pregnancy warning label. While it appears consumers believe 'drink responsibly' and standard drink messages to be a warning label, past research indicates that the standard drink information on products often simply enables young adult drinkers to select the strongest drinks for the lowest cost, thus actually encouraging heavy drinking [35].

The current study found that frequency of binge drinking increased the odds of exposure to the logo, labels, and visiting the DrinkWise website. Prior research indicates that high-risk drinking is associated with greater awareness of warning label messages $[25,23]$. Additional longitudinal research is required to determine whether the utilisation of the DrinkWise website reduces the frequency of heavy 
Table. 4 Results of logistic regression models predicting awareness of alcohol warning labels

\begin{tabular}{|c|c|c|c|c|c|c|}
\hline & \multicolumn{2}{|c|}{ It is safest not to drink while pregnant ${ }^{a}$} & \multicolumn{2}{|c|}{ Is your drinking harming yourself or others? } & \multicolumn{2}{|c|}{ Kids and alcohol don't mix } \\
\hline & OR $(95 \% \mathrm{Cl})$ & $\mathrm{p}$ & OR $(95 \% \mathrm{Cl})$ & $p$ & OR $(95 \% \mathrm{Cl})$ & $p$ \\
\hline \multicolumn{7}{|l|}{ Gender } \\
\hline Male & 1.00 & & 1.00 & & 1.00 & \\
\hline Female & $1.22(0.78-1.90)$ & .391 & $0.77(0.44-1.34)$ & .350 & $0.58(0.29-1.16)$ & .125 \\
\hline Age & Wald $x^{2} p<.001$ & & Wald $x^{2} p=.026$ & & Wald $x^{2} p=.004$ & \\
\hline $18-24$ & 1.00 & & 1.00 & & 1.00 & \\
\hline $25-34$ & $0.97(0.56-1.64)$ & .873 & $0.56(0.29-1.11)$ & .096 & $0.40(0.19-0.84)$ & .016 \\
\hline $35-45$ & $0.31(0.18-0.54)$ & $<.001$ & $0.41(0.21-0.78)$ & .007 & $0.29(0.14-0.60)$ & .001 \\
\hline \multicolumn{7}{|l|}{ Education } \\
\hline Less than tertiary & 1.00 & & 1.00 & & 1.00 & \\
\hline Tertiary or above & $0.95(0.62-1.46)$ & .818 & $1.57(0.92-2.68)$ & .095 & $1.97(1.02-3.84)$ & .045 \\
\hline Binge drinking & $1.40(1.13-1.72)$ & .002 & $1.55(1.20-2.00)$ & .001 & $1.54(1.15-2.05)$ & .004 \\
\hline Main alcoholic drink & Wald $x^{2} p=.204$ & & Wald $x^{2} p=.250$ & & Wald $x^{2} p=.069$ & \\
\hline Beer & 1.00 & & 1.00 & & 1.00 & \\
\hline Wine & $1.23(0.70-2.16)$ & .472 & $1.72(0.89-3.31)$ & .108 & $2.51(1.04-6.06)$ & .041 \\
\hline Spirits & $0.88(0.48-1.61)$ & .671 & $1.36(0.65-2.85)$ & .418 & $1.16(0.42-3.20)$ & .776 \\
\hline Pre-mix & $0.48(0.24-0.98)$ & .045 & $0.63(0.25-1.59)$ & .325 & $0.81(0.25-2.67)$ & .740 \\
\hline Cider & $0.82(0.28-2.39)$ & .718 & $1.41(0.34-5.85)$ & .640 & $1.38(0.23-8.20)$ & .725 \\
\hline Other & $0.95(0.30-2.97)$ & .929 & $1.19(0.31-4.56)$ & .796 & $4.22(1.22-14.68)$ & .023 \\
\hline \multicolumn{7}{|c|}{ Drink directly from can or bottle } \\
\hline Never/not often & 1.00 & & 1.00 & & 1.00 & \\
\hline At least sometimes & $1.75(1.10-2.77)$ & .018 & $2.24(1.21-4.13)$ & .010 & $2.90(0.93-3.88)$ & .077 \\
\hline \multicolumn{7}{|c|}{ Support for health warning labels } \\
\hline Neutral or opposed & 1.00 & & 1.00 & & 1.00 & \\
\hline Support/strongly support & $2.48(1.41-4.37)$ & .002 & $2.53(1.25-5.12)$ & .010 & $2.65(1.06-6.60)$ & .037 \\
\hline
\end{tabular}

${ }^{\mathrm{a} A w a r e n e s s}$ of any of the three pregnancy warning labels

Note. Data weighted by age, sex, and state of residence

drinking occasions. Younger adults in the current study were also more likely to be aware of the warning labels. Australians aged 18-24 years tend to consume greater quantities of alcoholic beverages than drinkers of any other age group [2]. The higher alcohol consumption amongst this age group would lead to a greater potential of exposure to warning labels, and thus, higher levels of awareness of warning labels than older drinkers [23]. Our findings are also consistent with international research that shows younger people and heavy drinkers have the greatest increase over time for recall of warning label messages, most likely due to a higher exposure to such messages $[36,5]$.

Some of the higher level of logo and label awareness among young people may also be hypothesised to be due to the increased proportion consuming alcohol directly from a can or bottle. The current study also found that those who consume directly from a can or bottle are more likely to be aware of the logo, labels and visit the website. The majority of $18-25$ year olds consume most of their alcohol within their home before going out to licensed venues [37], and it may be that this pre-drinking is more likely to be directly from the bottle or can. Posthoc analyses indicated that for our study, 18-24 year olds were significantly more likely to drink directly from a container than $35-45$ year olds $(\mathrm{OR}=2.19$; $95 \% \mathrm{CI}=1.22-3.93, p=.008)$. Previous research has also shown that students who drink directly from the alcohol container have a more accurate memory for the risks depicted on a warning label than students who poured their beverage into a glass [38]. Recent research indicates approximately $41 \%$ of heavy drinking occasions, and $50 \%$ of low-risk drinking occasions occur within a licensed venue [39]. With alcohol commonly served by the glass at licensed venues, and not in its original container, the likelihood of exposure to an alcohol warning label decreases. Thus, comprehensive warning label policy needs to include the requirement for the use of signs or posters in highly visible locations within licenced venues to reinforce the warning label 
Table. 5 Results of logistic regression models predicting visiting the DrinkWise website

\begin{tabular}{|c|c|c|}
\hline & OR $(95 \% \mathrm{Cl})$ & $p$ \\
\hline \multicolumn{3}{|l|}{ Gender } \\
\hline Male & 1.00 & \\
\hline Female & $0.23(0.08-0.63)$ & .004 \\
\hline Age & Wald $x^{2} p=.304$ & \\
\hline $18-24$ & 1.00 & \\
\hline $25-34$ & $0.80(0.27-2.38)$ & .682 \\
\hline $35-45$ & $0.46(0.15-1.42)$ & .176 \\
\hline \multicolumn{3}{|l|}{ Education } \\
\hline Less than tertiary & 1.00 & \\
\hline Tertiary or above & $1.27(0.50-3.26)$ & .613 \\
\hline Binge drinking & $1.56(1.07-2.78)$ & .022 \\
\hline Main alcoholic drink & Wald $x^{2} p=.004$ & \\
\hline Beer & 1.00 & \\
\hline Wine & $10.25(3.35-33.36)$ & $<.001$ \\
\hline Spirits & $6.23(1.57-24.73)$ & .009 \\
\hline Pre-mix & $0.77(0.08-7.87)$ & .827 \\
\hline Cider & $2.45(0.16-38.05)$ & .520 \\
\hline Other & $2.78(0.24-32.27)$ & .413 \\
\hline \multicolumn{3}{|c|}{ Drink directly from can or bottle } \\
\hline Never/not often & 1.00 & \\
\hline At least sometimes & $3.50(1.11-11.02)$ & .032 \\
\hline \multicolumn{3}{|c|}{ Support for health warning labels } \\
\hline Neutral or opposed & 1.00 & \\
\hline Support/strongly support & $4.27(1.09-16.80)$ & .038 \\
\hline \multicolumn{3}{|c|}{ Recognition of the 'Get the facts' logo } \\
\hline No & 1.00 & \\
\hline Yes & $7.25(2.50-21.01)$ & $<.001$ \\
\hline
\end{tabular}

Note. Data weighted by age, sex, and state of residence

messages and reach consumers that may not see warnings on alcohol containers. Such a requirement would be in line with the successful current tobacco control policies in Australia [40, 41].

Interestingly, while young adults were more likely to recognise the logo and warning labels they were not more likely to have visited the website. Studies with tobacco smokers have found that, in line with cognitive dissonance theory [42], when confronted with graphic warning labels, some smokers may report more positive cognitions about smoking [43] and rationalise their behaviour by changing their beliefs $[44,45]$. It may be theorised that young people are rationalising their drinking behaviour through decreased perceptions of risk [45]; these groups may believe that they do not need to 'Get the facts'. If alcohol warning labels are to be effective, messages targeted at specific subpopulations need to be developed [46].
While there was a low rate of recognition for the 'Get the Facts' logo, those who did recognise the logo were seven times more likely to have visited the DrinkWise website. While the current study asked participants if they learned new information from the DrinkWise website, the number of participants who reported having visited the website was too low to conduct any meaningful analysis. Further research is needed to evaluate the effectiveness of a consumer targeted alcohol control website. There is also a need to ensure that information presented on a consumer information website is evidence-based, useful and provides practical, new advice. Currently, the DrinkWise website is used to create an impression of social responsibility, and does not promote evidencebased interventions and alcohol-harm reduction strategies [13]. For instance, while there is strong evidence that increasing the price of alcohol through increased taxation leads to a decline in consumption, DrinkWise does not support such an intervention [13]. Therefore, the establishment of a website by an independent, nonbiased source is required to ensure consumers are provided with accurate and evidence-based information. In order to improve consumer utilisation of such a website, the size of warnings and the frequency with which warning labels appear on products need to increase. Additionally, promotional strategies for an independent alcohol awareness website could be implemented to boost website traffic.

\section{Limitations}

The current study recruited participants using an online research panel, which may limit the external validity of the study. However, in line with recommendations the data have been weighted to be more representative of the population [47]. Additionally, the current study was cross-sectional in design, with longitudinal research required to track changes in cognitions and behaviours of consumers after exposure to warning labels [17]. Further, given the number of analyses conducted, caution must be used when interpreting findings that were not part of a systematic pattern of effects.

\section{Conclusions}

The current study demonstrates low awareness of Australian alcohol warning labels, and lack of consumer use of the industry-funded DrinkWise website. The finding that drinking alcohol directly from the container increases exposure to warnings suggests that the use of warnings in other locations, such as at point of sale and within alcohol advertisements [5-8], will help to reinforce such health warning messages. Given that the majority of the Australian public support the introduction of mandatory health warning labels for alcohol products [46], and the success of tobacco labelling 
[7], graphic, highly visible alcohol warning labels placed on the front of products have the potential to reduce alcohol consumption and alcohol-related harms [11].

\section{Abbreviations}

US: United States; AUDIT-C: Alcohol Use Disorders Identification Test-C; OR: Odds ratio $95 \%$ Cl: $95 \%$ confidence intervals.

\section{Competing interests}

Peter Miller receives funding from Australian Research Council and Australian National Health and Medical Research Council, grants from NSW Government, National Drug Law Enforcement Research Fund, Foundation for Alcohol Research and Education, Cancer Council Victoria, Queensland government and Australian Drug Foundation, travel and related costs from Australasian Drug Strategy Conference. He is affiliated with academic journal Addiction. He has acted as a paid expert witness on behalf of a licensed venue and a security firm.

\section{Authors' contributions}

KC, FM and PGM designed the study. FM and IRB managed data collection and preliminary analyses. KC analysed the data and interpreted the results. KC drafted the manuscript with contributions from all authors. All authors read and approved the final manuscript.

\section{Acknowledgements}

KC is funded by the Faculty of Health, Deakin University. FM is funded by a PhD Scholarship at Deakin University. IRB and PGM are funded by the School of Psychology, Deakin University. Data collection and manuscript publication was funded by the School of Psychology, Deakin University.

Received: 13 May 2015 Accepted: 14 August 2015

Published online: 22 August 2015

\section{References}

1. World Health Organization. Global status report on alcohol and health. Geneva: WHO; 2011.

2. Australian Institute of Health and Welfare. National Drug Strategy Household Survey detailed report 2013, Drug statistics, vol. 28 PHE 183; 2013. Canberra: AlHW; 2014.

3. National Health and Medical Research Council. Australian guidelines to reduce health risks from drinking alcohol. Canberra: Commonwealth Government of Australia; 2009.

4. Foundation for Alcohol Research and Education. Annual alcohol poll: Attitudes and behaviours. Canberra: FARE; 2014.

5. Stockwell T. A review of research into the impacts of alcohol warning labels on attitudes and behaviour. Centre for Addictions Research of BC: British Columbia, Canada; 2006.

6. Foundation for Alcohol Research and Education. Alcohol product labelling: Health warning labels and consumer information. Deakin West, ACT: FARE; 2010.

7. Wilkinson C, Room R. Warnings on alcohol containers and advertisements: International experience and evidence on effects. Drug Alcohol Rev. 2009:28:426-43.

8. Eliott J, Miller E. Alcohol and cancer: the urgent need for a new message. MJA. 2014;200:71-2.

9. Foundation for Alcohol Research and Education. Alcohol health warning labels: Attitudes and perceptions. Canberra: FARE; 2011.

10. Anderson P, Chisholm D, Fuhr DC. Effectiveness and cost-effectiveness of policies and programmes to reduce the harm caused by alcohol. Lancet. 2009;373:2234-46.

11. Hammond D. Health warning messages on tobacco products: a review. Tob Control. 2011;20:327-37.

12. Babor TF. Alcohol research and the alcoholic beverage industry: issues, concerns and conflicts of interest. Addiction. 2009:104:34-47.

13. Miller PG, de Groot F, McKenzie S, Droste N. Vested interests in addiction research and policy. Alcohol industry use of social aspect public relations organizations against preventative health measures. Addiction. 2011:106:1560-7.

14. Australia and New Zealand Food Regulation Ministerial Council. Labelling logic: Review of food labelling law and policy (2011). Canberra: Commonwealth of Australia; 2011.
15. McCambridge J, Kypri K, Miller P, Hawkins B, Hastings G. Be aware of Drinkaware. Addiction. 2014;109:519-24.

16. Foundation for Alcohol Research and Education. Annual label audit. Canberra: FARE; 2013.

17. Jones S, Gordon R. Alcohol warning labels: Are they effective? Canberra: Australian Healthcare and Hospitals Association

18. Thomas M. Alcohol warning labels - do they work? Canberra: Department of Parliamentary Services; 2012.

19. Ferrence R, Hammond D, Fong G. Warning labels and packaging. In: Bonnie R, Stratton K, Wallace R, editors. Ending the tobacco problem: blueprint for the nation. Committee on Reducing Tobacco Use: Strategies, barriers, and consequences. Washington: National Academy Press; 2007. p. 435-48.

20. Smith S, Atkin C, Roznowski J. Are "drink responsibly" alcohol campaigns strategically ambiguous? Health Commun. 2006;20:1-11.

21. Scholes-Balog K, Heerde J, Hemphill S. Alcohol warning labels: unlikely to affect alcohol-related beliefs and behaviours in adolescents. Aust N Z J Public Health. 2012;6:524-9.

22. Thomas G, Gonneau G, Poole N, Cook J. The effectiveness of alcohol warning labels in the prevention of fetal alcohol spectrum disorder: A brief review. The International Journal of Alcohol and Drug Research. 2014;3:91-103.

23. Mazis M, Morris L, Swasy J. Longitudinal study of awareness, recall, and acceptance of alcohol warning labels. Appl Behav Sci Rev. 1996;4:111-20.

24. Tam TW, Greenfield TK. Do alcohol warning labels influence men's and women's attempts to deter others from driving when intoxicated? Human Factors and Ergonomics in Manufacturing \& Service Industries. 2010;20:538-46.

25. Greenfield T, Graves K, Kaskutas L. Long-term effects of alcohol warning labels: Findings from a comparison of the United States and Ontario. Canada Psychology \& Marketing. 1999;16:261-82

26. Andrews J. The effectiveness of alcohol warning labels: A Review and extension. Am Behav Sci. 1995;38:622-32.

27. Australian Government Department of Health. Evaluation of the voluntary labelling initiative to place pregnancy health warning labels of alcohol products. Canberra: Commonwealth of Australia; 2014.

28. Bush K, Kivlahan DR, McDonell MB, Finn SD, Bradley KA. The audit alcohol consumption questions (AUDIT-C): An effective brief screening test for problem drinking. Arch Intern Med. 1998;158:1789-95.

29. Dawson DA, Grant BF, Stinson FS, Zhou Y. Effectiveness of the derived Alcohol Use Disorders Identification Test (AUDIT-C) in screening for alcohol use disorders and risk drinking in the US General Population. Alcoholism: Clinical \& Experimental Research. 2005:29:844-54.

30. Meneses-Gaya C, Zuardi AW, Loureiro SR, Hallak JE, Trzesniak C, de Azevedo Marques JM, et al. Is the full version of the AUDIT really necessary? Study of the validity and internal construct of its abbreviated versions. Alcoholism: Clinical \& Experimental Research. 2010;34:1417-24.

31. StataCorp. Stata statistical software: release 12. College Station, TX: StataCorp LP; 2011.

32. Australian Bureau of Statistics. 2011 Census of population and housing. Canberra: ABS; 2011.

33. O'Brien RM. A caution regarding rules of thumb for variance inflation factors. Drug Alcohol Rev. 2007;41:673-90.

34. Jones S, Gregory P. Health warning labels on alcohol products - the views of Australian university students. Contemporary Drug Problems. 2010;37:109-37.

35. Jones SC, Gregory P. The impact of more visible standard drink labelling on youth alcohol consumption: Helping young people drink (ir)responsibly? Drug Alcohol Rev. 2009;28:230-4.

36. Greenfield T. Warning labels: evidence of harm reduction from long-term American surveys. In: Plant M, Single E, Stockwell T, editors. Alcohol: Minimising the harm. London: Free Association Books; 1997. p. 102-25.

37. Dietze PM, Livingston M, Callinan S, Room R. The big night out: What happens on the most recent heavy drinking occasion among young Victorian risky drinkers? Drug Alcohol Rev. 2014;33:346-53.

38. Nohre L, MacKinnon D, Stacy A, Pentz M. The association between adolescents' receiver characteristics and exposure to alcohol warning labels. Psychol Mark. 1999;16:245-59.

39. Callinan S, Livingston M, Dietze $P$, Room R. Heavy drinking occasions in Australia: Do context and beverage choice differ from low-risk drinking occasions? Drug Alcohol Rev. 2014;33:354-7. 
40. Department of Health State of Victoria. Tobacco retailer guide: Incorporating amendments passed by the Victorian Parliament in 2009. Melbourne: Prevention and Population Health Branch, Victorian Government, Department of Health; 2010

41. Prevention and Population Health Branch, Victorian Government, Department of Health. Tobacco Act 1987. Act No 81/1987. 1987.

42. Festinger L. A theory of cognitive dissonance. Stanford, California: Stanford University Press; 1957.

43. Süssenbach P, Niemeier S, Glock S. Effects of and attention to graphic warning labels on cigarette packages. Psychol Health. 2013;28:1192-206.

44. Fotuhi O, Fong GT, Zanna MP, Borland R, Yong H-H, Cummings KM. Patterns of cognitive dissonance-reducing beliefs among smokers: a longitudinal analysis from the International Tobacco Control (ITC) Four Country Survey. Tob Control. 2013;22:52-8.

45. Glock S, Kneer J. Are deterrent pictures effective? The impact of warning labels on cognitive dissonance in smokers. Applied Psychology: Health and Well-Being. 2009:1:356-73.

46. Thomson LM, Vandenberg B, Fitzgerald JL. An exploratory study of drinkers views of health information and warning labels on alcohol containers. Drug Alcohol Rev. 2012;31:240-7.

47. American Association for Public Opinion Research. AAPOR report on online panels. Deerfield, IL: AAPOR; 2010.

\section{Submit your next manuscript to BioMed Central and take full advantage of:}

- Convenient online submission

- Thorough peer review

- No space constraints or color figure charges

- Immediate publication on acceptance

- Inclusion in PubMed, CAS, Scopus and Google Scholar

- Research which is freely available for redistribution 